\title{
Adição de resíduo do polimento de porcelanato em argamassas de restauro à base de cal
}

\section{(Addition of porcelain tile polishing residue in lime mortars for restoration)}

\author{
S. B. Breitenbach ${ }^{1,2}$, O. C. Santos ${ }^{1,2}$, J. C. S. Andrade, R. M. Nascimento ${ }^{2}$, A. E. Martinelli ${ }^{2}$ \\ 'Instituto Federal de Ciência e Tecnologia da Bahia, R. Emidio Santos s/n, Salvador, BA \\ ${ }^{2}$ Programa de Pós-Graduação em Ciência e Engenharia de Materiais, \\ Universidade Federal do Rio Grande do Norte, Natal, RN \\ ${ }^{3}$ Departamento de Engenharia de Materiais, Faculdade de Tecnologia Universidade Federal do Amazonas, \\ Av. Rodrigo Otávio Jordão Ramos 3000, Manaus, AM \\ silviabb@ifba.edu.br,engcruz@ig.com.br,jean.engmateriais@gmail.com, \\ rubensmaribondo@gmail.com,martinelli.ufrn@gmail.com
}

\begin{abstract}
Resumo
As argamassas de revestimento aplicadas ao restauro de obras e edifícios históricos devem ser compatíveis com os materiais pré-existentes, contribuindo com a preservação e reabilitação do patrimônio edificado sem comprometimento de seu valor arquitetônico. As argamassas mais empregadas no restauro de edifícios antigos são os traços de cal e agregado miúdo na razão de 1:3 por não serem tão duras quanto as de cimento. $\mathrm{O}$ desempenho e a durabilidade dessas argamassas podem ser melhorados, reduzindo o número de intervenções. A adição de resíduos finos pode contribuir com estes objetivos por meio do preenchimento de poros da argamassa no estado endurecido. $\mathrm{O}$ resíduo do polimento do porcelanato (RPP) possui granulometria fina e pode ser aplicado substituindo parcialmente o agregado miúdo. Assim, o objetivo desse trabalho foi avaliar o efeito da adição de RPP em argamassas de restauro à base de cal, substituindo o agregado fino. Concentrações entre 5 e 30\% foram estudadas e o comportamento comparado ao da argamassa padrão. Foram realizados ensaios de consistência, densidade de massa aparente, retenção de água e teor de ar incorporado no estado fresco. Para a avaliação do estado endurecido, foram moldados corpos de prova prismáticos ensaiados aos 90 dias de idade para avaliação da resistência mecânica à tração, flexão e compressão e aderência. Todos os ensaios realizados são normatizados pela ABNT. Os resultados mostraram que a substituição de areia por RPP resultou em maior densidade e compacidade em consequência da diminuição no teor de ar incorporado. As argamassas com concentrações de RPP entre 10 e 20\% apresentaram melhor conjunto de propriedades no estado endurecido, com ganho em retração livre, maior resistência mecânica e aderência. A adição de RPP em substituição parcial da areia resultou em argamassas com melhor desempenho que sugere maior durabilidade, contribuindo para o restauro arquitetônico e preservação do patrimônio histórico com menor número de intervenções.
\end{abstract}

Palavras-chave: argamassa de cal, restauração, resíduo do polimento de porcelanato.

\begin{abstract}
Mortar coatings applied to historic buildings and artwork must be compatible with the pre-existing materials, thus contributing with both the restoration and preservation of heritage without affecting its architectonic value. Lime mortars consisting of fine aggregate ratio of 1:3 are softer than cement mortars and therefore more adequate for restoration. The performance and durability of the conventional lime mortar can be further improved in order to reduce the number of interventions. The addition of fine residues can contribute to this goal as they fill the pores of the hardened mortar. The residue of porcelain tile polishing $(R P P)$ is a fine material and can be added to the mortar partially replacing the fine aggregate. Therefore, the present study aimed at evaluating the effect of the addition of RPP on the fresh and hardened states of the lime mortar. Contents from 5 to $30 \mathrm{wt} \%$ of RPP were investigated and the properties of the corresponding mortars were compared to those of the conventional mortar. In the fresh state, consistency, density, water retention and air content were measured. Rectangular samples of each mortar composition were then dried and aged during 90 days to analyze the mechanical strength and adherence. All tests are standardized by ABNT. The results revealed that mortars containing RPP depicted higher density and compactness as a consequence of the reduction in the air content. Mortars with RPP contents between 10 and 20\% showed enhanced properties in the hardened state compared to the RPP-free mortar, including better retraction behavior, higher mechanical and adherence strength. The addition of RPP, partially replacing the fine aggregate in lime mortar, resulted in mortar compositions with improved overall behavior for restoration, and possibly longer durability, thus contributing to the architectural restoration and preservation of historical heritage with fewer interventions.
\end{abstract}

Keywords: lime mortar, restoration, porcelain tile polishing residue.

\section{INTRODUÇÃO}

As argamassas de restauro devem proporcionar as características necessárias à restauração de edificações históricas evitando intervenções radicais, perdas e danos ao patrimônio. As argamassas antigas guardam 
evidências sobre a história construtiva da edificação, seus métodos e materiais empregados. As argamassas de cal são as mais comumente usadas na restauração moderna por sua capacidade de manter as características dos edifícios antigos, harmonizando-se esteticamente com as alvenarias tradicionais. Além disso, são materiais de alta plasticidade, o que favorece a conservação das alvenarias tradicionais, pois absorvem os efeitos agressivos de agentes atmosféricos. Apesar da compatibilidade, o desempenho e a durabilidade dessas argamassas podem ser melhorados. O problema da degradação e potencial restauração das argamassas, especialmente em edifícios históricos, tem chamado pouca atenção de pesquisadores no campo dos materiais de construção. Como consequência, muitas vezes a consolidação e a restauração das construções históricas, em especial dos rebocos, terminam por aumentar a sua degradação, após um período inicial de aparente melhora [1]. Nos últimos anos, a conservação de edifícios históricos começa a ter certa importância em nosso país. A inexistência de materiais comerciais mais adequados justifica a necessidade de aprimorar os materiais existentes ou propor novos materiais.

A granulometria fina do resíduo do polimento de porcelanato (RPP) desperta interesse pela possibilidade de preenchimento dos poros presentes na argamassa tradicional à base de cal e agregado fino. Com isso, há possibilidade de melhorias nas propriedades ligadas ao desempenho mecânico, aderência e durabilidade desse material. O porcelanato polido requer uma etapa de polimento durante sua produção a fim de nivelar, retirar riscos e defeitos e dar brilho à superfície do produto final. Essa etapa do processamento gera grande quantidade de resíduo, particularmente com o aumento da produção que vem ocorrendo nos últimos anos. O RPP é constituído de uma mistura de material cerâmico oriundo do polimento do porcelanato e material abrasivo, geralmente composto por partículas de diamante ou carbeto de silício aglomerados por cimentos à base de cloretos magnesianos [2]. Ele é descartado diretamente em aterros, apesar do seu potencial de aplicação.

O consumo de agregado miúdo para concreto e argamassa no Brasil é em torno de 210 milhões de toneladas por ano [3]. Atualmente, grande parte do agregado miúdo natural (areia) é extraída de leitos de rios, provocando a retirada da cobertura vegetal e a degradação dos cursos de água, com impacto ao meio ambiente. Órgãos responsáveis pela fiscalização do meio ambiente têm coibido esta prática, pois o Código Florestal considera como áreas de preservação permanente as florestas e demais vegetações naturais situadas ao longo dos rios. Com isso, a areia que abastece a construção civil vem, cada vez mais, de regiões mais afastadas, ocasionando aumento no preço do produto. Desta forma, surge a necessidade de se buscar alternativas para substituição das areias extraídas dos rios e que possam manter ou melhorar o desempenho das argamassas, incluindo as de cal. Com base neste cenário, o objetivo deste trabalho foi estudar o efeito da adição de RPP em argamassa de restauração com traço de cal e areia na razão de 1:3 em volume. Adições de 5 a $30 \%$ de RPP foram empregadas em substituição à areia. Foram realizados ensaios de caracterização no estado fresco e endurecido visando identificar possíveis melhorias no desempenho e na durabilidade.

\section{MATERIAIS E MÉTODOS}

As argamassas produzidas utilizaram como materiais de partida cal hidratada comercial (Carbomil, Fortaleza, Brasil) originária de lote único, areia de rio comercial e resíduo do polimento de porcelanato. O RPP foi primeiramente seco em estufa a $100{ }^{\circ} \mathrm{C}$, desaglomerado em moinho com bolas de moagem de vários diâmetros, por $2 \mathrm{~h}$ e classificado em peneira com abertura de $0,15 \mathrm{~mm}\left(\mathrm{ABNT} \mathrm{n}^{\circ} 100\right)$. O resíduo foi caracterizado por granulometria a laser, microscopia eletrônica de varredura, difratometria de raios $\mathrm{X}$ e fluorescência de raios X. A massa específica e massa unitária foram também determinadas. A argamassa à base de cal e areia foi utilizada como referência (A/0/REF) para a análise dos efeitos da substituição do resíduo. O traço volumétrico 1:3 (cal:areia) é de utilização frequente na formulação de argamassas de cal aérea utilizadas como camadas de emboço. Foram formuladas argamassas com a substituição da areia por RPP, conforme Tabela I. A quantidade de água utilizada nas formulações estudadas foi obtida em estudos preliminares, definindo a consistência por espalhamento em $260 \pm 5 \mathrm{~mm}$. Para conversão do traço em volume para massa utilizou-se a razão, obtendo-se 1:9,117, conforme:

$$
\frac{\text { Pcal.Ycal }}{\text { Ycal }}: \frac{\text { Pagr.Yagr }}{\text { Ycal }}
$$

onde, Pcal e Pagr são as proporções no traço da argamassa de cal hidratada e agregado miúdo, respectivamente, em volume aparente $\left(\mathrm{cm}^{3}\right)$, e Ycal e Yagr são as massas unitárias da cal hidratada no estado solto e do agregado miúdo no estado solto e seco, respectivamente $\left(\mathrm{em} \mathrm{g} / \mathrm{cm}^{3}\right)$.

$\mathrm{O}$ estado fresco das argamassas foi caracterizado por meio de ensaios normatizados pela ABNT de índice de consistência [4], densidade de massa aparente e teor de ar incorporado [5], e retenção de água [6]. A caracterização física e mecânica das argamassas no estado endurecido foi realizada por meio de ensaios de resistência à compressão e flexão na tração, retração e aderência, em corpos de prova $(\mathrm{CPs})$ prismáticos. Foram confeccionados 15 CPs de $40 \mathrm{~mm}$ x 40 $\mathrm{mm} \times 160 \mathrm{~mm}$ para cada argamassa. O procedimento para moldagem adotado foi o método de choque estabelecido por norma ABNT [7]. Após 7 dias, os CPs foram desmoldados e curados ao ar, em local coberto, durante 90 dias. A resistência à tração na flexão e a resistência à compressão foram determinadas com 4 CPs por argamassa. A norma permite que primeiramente se ensaie o $\mathrm{CP}$ à tração na flexão e, em seguida, que o mesmo seja ensaiado à compressão [8]. Para a realização do ensaio de resistência à tração na flexão, demarcou-se o eixo do CP para garantir a aplicação da carga no centro do mesmo. Os ensaios foram realizados em uma máquina universal da Shimadzu, Autograph AG-X. A velocidade de carga utilizada para o ensaio de resistência à com- 
Tabela I - Composições das argamassas.

[Table I - Mortar compositions.]

\begin{tabular}{ccccc}
\hline Argamassa & $\begin{array}{c}\text { Fração de RPP } \\
(\% \text { em massa })\end{array}$ & Composição do traço & $\begin{array}{c}\text { Dosagem de materiais }(\mathrm{g}) \text { para } \\
15 \text { moldes }\end{array}$ & $\begin{array}{c}\text { Quantidade de } \\
\text { água }(\mathrm{mL})\end{array}$ \\
\hline A/0/REF & 0 & cal $:$ areia & $769: 7011$ & 1461,00 \\
A/05/RPP & 5 & cal : resíduo : areia & $769: 350,55: 6661,00$ & 1538,00 \\
A/10/RPP & 10 & cal : resíduo : areia & $769: 701,00: 6310,00$ & 1615,00 \\
A/15/RPP & 15 & cal : resíduo : areia & $769: 1051,65: 5959,00$ & 1707,00 \\
A/20/RPP & 20 & cal : resíduo : areia & $769: 1402,20: 5608,80$ & 1845,60 \\
A/25/RPP & 25 & cal : resíduo : areia & $769: 1752,75: 5258,25$ & 1991,71 \\
A/30/RPP & 30 & cal : resíduo : areia & $769: 2103,30: 4907,70$ & 2130,13 \\
\hline
\end{tabular}

pressão e para o ensaio de resistência à tração na flexão foi de $0,25 \mathrm{~N} / \mathrm{s}$. A absorção de água das argamassas foi avaliada por ensaio normatizado que tem como princípio medir a absorção de água pelos poros de 3 CPs para cada argamassa [9]. A partir da colocação dos CPs na água, determinou-se a massa de cada corpo de prova após 10 e 90 min. A absorção de água por capilaridade foi calculada para cada tempo e expressa em $\mathrm{g} / \mathrm{cm}^{2}$, de acordo com a equação:

$$
\mathrm{At}=\frac{\mathrm{mt}-\mathrm{mo}}{16}
$$

onde, At é a absorção de água por capilaridade, para cada tempo $\left(\mathrm{g} / \mathrm{cm}^{2}\right), \mathrm{mt}$ é a massa do $\mathrm{CP}$ em cada tempo $(\mathrm{g})$, mo é a massa inicial do corpo de prova $(\mathrm{g}), \mathrm{t}$ correspondeu ao tempo de 10 e $90 \mathrm{~min}$, e o valor 16 é a área do corpo de prova, em $\mathrm{cm}^{2}$.

A avaliação da retração das argamassas é indicativa de qualidade e durabilidade do material. Uma vez aplicada sobre uma base, a argamassa é impedida de retrair-se livremente por causa da aderência e são geradas tensões de tração, que podem levar à fissuração. Para este ensaio foram moldados 3 CPs de cada argamassa, em formas triplas de dimensões 2,5 $\mathrm{cm} \times 2,5 \mathrm{~cm} \times 28,5 \mathrm{~cm}$, conforme estabelecido pela norma de aderência da argamassa [10]. Este projeto de norma adota o valor máximo de retração aos 28 dias para argamassas de revestimento (emboço). $\mathrm{O}$ ambiente para armazenagem dos CPs foi controlado, mantendo a temperatura em $23 \pm 2{ }^{\circ} \mathrm{C}$ e umidade relativa do ar em $50 \pm 5 \%$. Os valores de retração foram medidos com a argamassa no estado endurecido após 7 dias de moldagem dos CPs, uma vez que antes deste prazo a resistência ao manuseio foi insuficiente. A leitura inicial em relógio comparador (precisão $0,001 \mathrm{~mm}$ ) foi feita logo após a desforma, seguindo-se outras medidas em intervalos de 7 dias até completar 28 dias. A norma [11] prescreve o método para determinação da resistência de aderência à tração de revestimento de paredes e tetos de argamassas inorgânicas. Este ensaio permite avaliar diretamente a aderência da argamassa ao suporte medindo a força necessária para o arrancamento (tração direta) de uma pastilha metálica previamente colada, bem como permite avaliar a compatibilidade da argamassa com o suporte. Os CPs foram aplicados sobre componentes de alvenaria em forma de painéis (Fig. 1), composto por 6 furações para

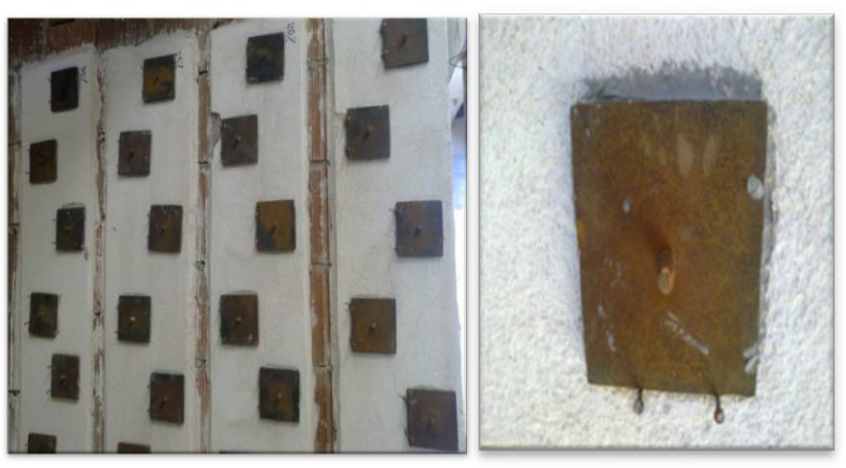

Figura 1: Imagem das amostras para ensaio de aderência à tração das argamassas.

[Figure 1: Images of samples for tensile adhesion test.]

colagem das pastilhas metálicas de seção quadrada com $100 \mathrm{~mm}$ de lado, para cada argamassa, espaçados entre si e dos cantos ou quinas em no mínimo $50 \mathrm{~mm}$. Para o ensaio, aplicou-se cola epóxi na interface entre a pastilha metálica e a argamassa e, em seguida, pressionou-se durante poucos minutos de forma a garantir o espalhamento da cola e a respectiva uniformidade da camada, removendo-se eventuais excessos. A colagem foi considerada concluída após um período mínimo de $1 \mathrm{~h}$. O arrancamento foi feito aplicando-se uma força perpendicular à pastilha. A taxa de aplicação da força foi controlada. Quando da aplicação gradual da força, o valor da tensão foi registrado em dinamômetro até a ruptura. O máximo valor registrado correspondeu à tensão de aderência. Os valores da tensão de aderência corresponderam aos valores médios dos seis ensaios efetuados em cada argamassa.

\section{RESULTADOS E DISCUSSÃO}

A composição química do RPP é apresentada na Tabela II. O resíduo apresentou elevada quantidade de $\mathrm{SiO}_{2}, \mathrm{Al}_{2} \mathrm{O}_{3}$ e $\mathrm{MgO}$, e baixa concentração de óxidos fundentes. Os altos teores de $\mathrm{SiO}_{2}$ e $\mathrm{Al}_{2} \mathrm{O}_{3}$ e o baixo teor de $\mathrm{Fe}_{2} \mathrm{O}_{3}$ e demais óxidos fundentes são característicos da composição de argilas utilizadas na fabricação de porcelanatos. Resíduos do material abrasivo $(\mathrm{SiC})$ são representados pela concentração de $\mathrm{SiO}_{2}$, já que a Tabela II representa o resultado de uma análise 
Tabela II - Composição química (\% em massa) do resíduo do polimento de porcelanato. [Table II - Chemical composition (wt\%) of the porcelain tile polishing residue.]

\begin{tabular}{cccccccc}
\hline $\mathrm{SiO}_{2}$ & $\mathrm{Al}_{2} \mathrm{O}_{3}$ & $\mathrm{MgO}$ & $\mathrm{CaO}$ & $\mathrm{K}_{2} \mathrm{O}$ & $\mathrm{SO}_{3}$ & $\mathrm{Fe}_{2} \mathrm{O}_{3}$ & Outros \\
\hline 64,0 & 21,7 & 5,4 & 2,6 & 2,0 & 1,8 & 1,0 & 0,5 \\
\hline
\end{tabular}

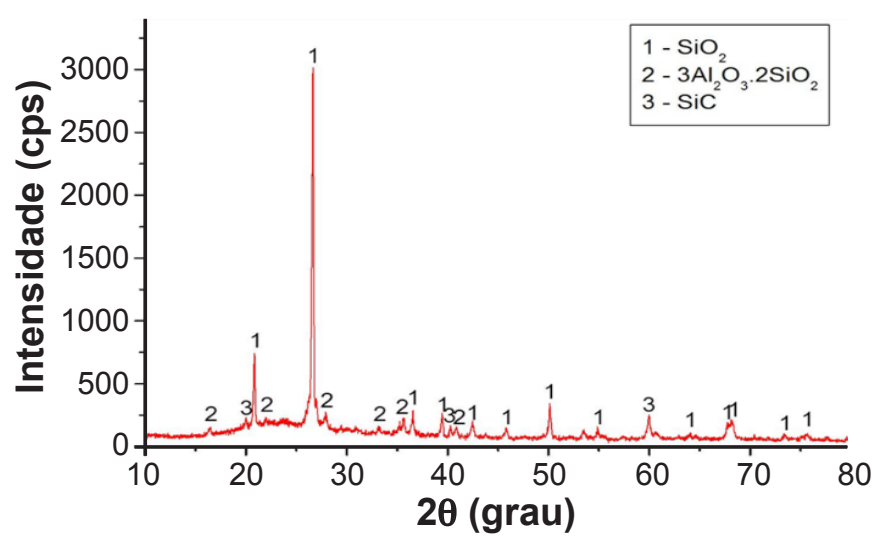

Figura 2: Difratograma de raios X do RPP. [Figure 2: X-ray diffraction pattern of RPP.]

de fluorescência de raios $X$ semiquantitativa expresso em equivalente em óxidos. A difração de raios X do RPP (Fig. 2) revelou que as fases predominantes foram quartzo e mulita oriundos da superfície do porcelanato e $\mathrm{SiC}$ do material abrasivo. A fração amorfa do difratograma representa, possivelmente, fases vítreas ricas em silício e alumínio.

A distribuição de tamanhos de partícula do RPP está apresentada na Fig. 3a. Os diâmetros variaram entre 1 e $44 \mu \mathrm{m}$. O diâmetro médio foi $5,93 \mu \mathrm{m}$ e os valores de $\mathrm{D}_{10}$, $\mathrm{D}_{50}$ e $\mathrm{D}_{90}$ foram, respectivamente, $1,27,5,44$ e $11,27 \mu \mathrm{m}$. Com base na granulometria, confirmou-se que o RPP é um material fino com potencial para o preenchimento de poros deixados na argamassa de cal. A Fig. 3b apresenta a morfologia das partículas do RPP. Podem-se observar detalhes dos cristais de quartzo com a presença de fraturas com formato irregular e angular, o que pode, a princípio, dificultar a trabalhabilidade das argamassas dosadas com este material.

Os valores de massa específica e massa unitária dos
Tabela III - Massa específica (ME) e massa unitária (MU) dos materiais de partida.

[Table III - Specific mass (ME) and unit mass (MU) of the starting materials.]

\begin{tabular}{ccc}
\hline & $\mathrm{ME}\left(\mathrm{g} / \mathrm{cm}^{3}\right)$ & $\mathrm{MU}\left(\mathrm{g} / \mathrm{cm}^{3}\right)$ \\
\hline Cal & 2,00 & 0,51 \\
Agregado miúdo & 2,61 & 1,55 \\
$\mathrm{RPP}$ & 2,32 & 0,70 \\
\hline$R P P$ - residuo do polimento do porcelanato. &
\end{tabular}

materiais utilizados na formulação das argamassas estão listados na Tabela III. A massa específica do RPP foi inferior à do agregado miúdo. A redução do tamanho de partículas do agregado para o resíduo implica em maior superfície específica, que auxilia na ligação entre o agregado e o aglomerante. O RPP possuiu massa unitária maior que a do aglomerante. Assim, os resíduos podem contribuir para o preenchimento dos poros presentes entre agregado (areia) e aglomerante (cal).

\section{Caracterização das argamassas no estado fresco}

O índice de consistência das argamassas está ilustrado na Fig. 4a. A adição de RPP exigiu maior quantidade de água em relação à argamassa padrão. Houve maior mobilidade e interação entre as partículas com diâmetros menores que 75 $\mu \mathrm{m}$ ocasionadas, principalmente, pela presença de finos com diâmetros médios de $6,3 \mu \mathrm{m}$ (cal) e 5,9 $\mu \mathrm{m}$ (RPP) na argamassa aumentando a área superficial e, consequentemente, o consumo de água. A presença de RPP também aumentou a densidade de massa das argamassas no estado fresco até o teor de $15 \%$ de RPP, em relação à argamassa de referência (Fig. 4b). Para concentrações maiores de RPP a densidade

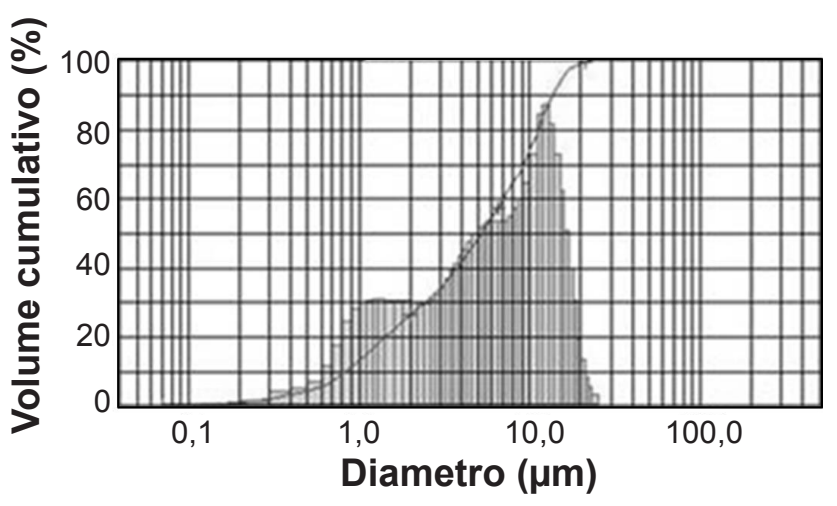

a)

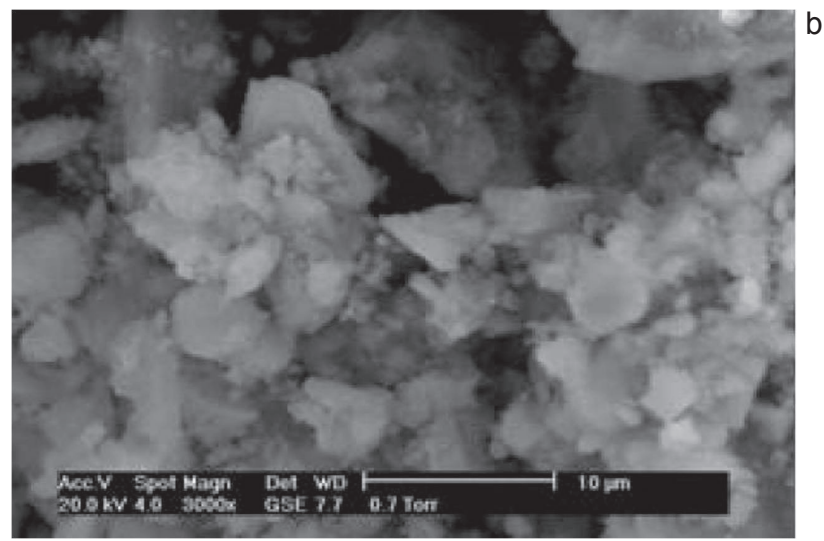

Figura 3: Distribuição de tamanhos de partículas (a) e micrografia obtida por microscopia eletrônica de varredura (b) do RPP. [Figure 3: Particle size distribution (a) and SEM micrograph (b) of RPP.] 

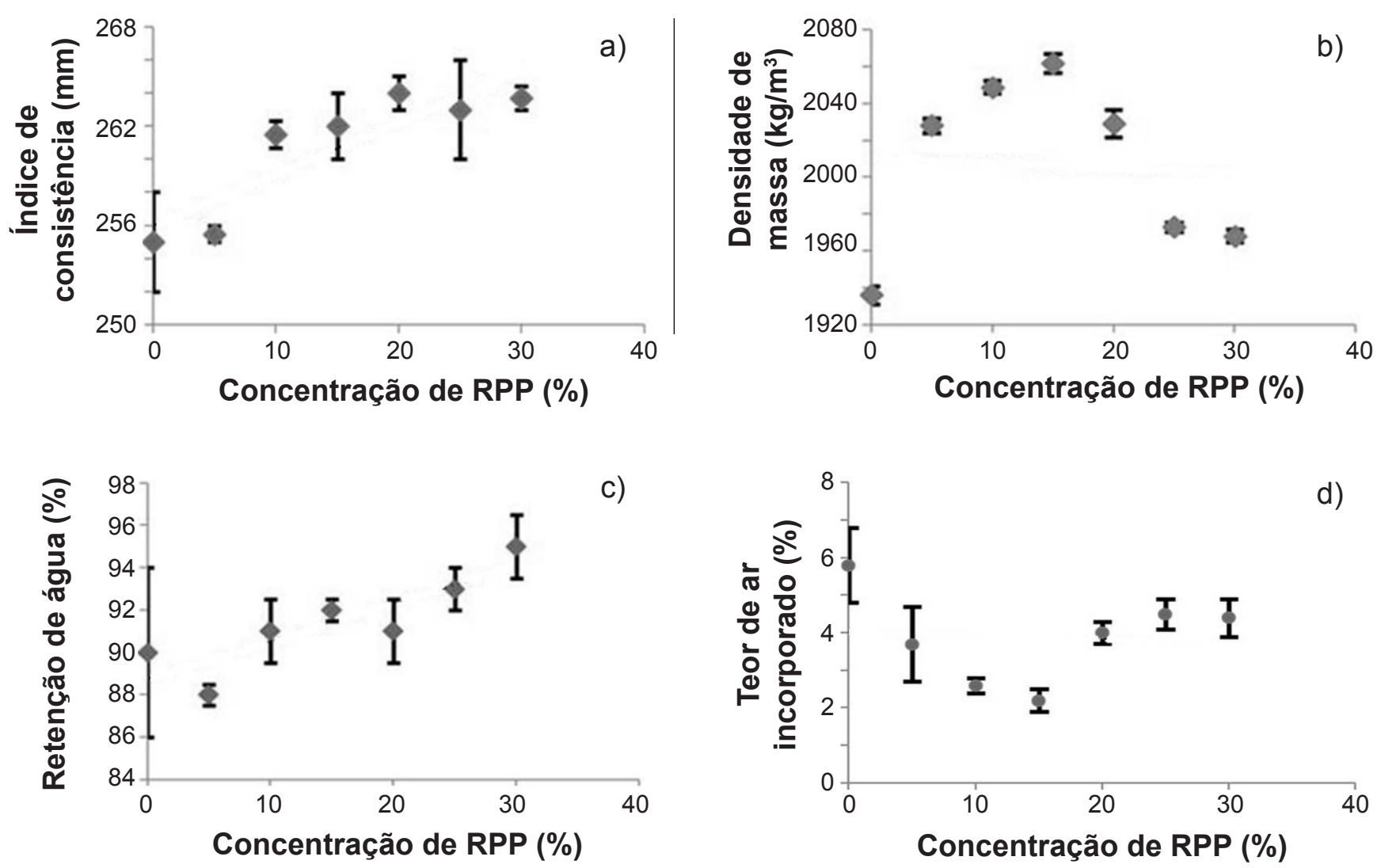

Figura 4: Índice de consistência (a), densidade de massa (b), retenção de água (c) e teor de ar incorporado (d) das argamassas em função da concentração de RPP.

[Figure 4: Consistency index (a), density (b), water retention (c), and air content (d) of mortars as a function of RPP content.]

de massa diminuiu, mas permaneceu maior que a da argamassa padrão. Tal fato ocorreu devido à maior quantidade de finos e consequentemente maior consumo de água. A densidade das argamassas influencia diretamente o comportamento da argamassa, incluindo a trabalhabilidade, o que afeta o espalhamento e a aderência entre a argamassa endurecida e o substrato. No tocante à classificação, os resultados mostraram que não houve variação entre as argamassas formuladas com RPP e a de referência, sendo todas na faixa central da tabela de classificação estabelecida pela ABNT [12].

Os valores apresentados na Fig. $4 \mathrm{c}$ mostram que todas as argamassas estudadas apresentaram alta retenção de água, o que sugeriu bom desempenho mediante determinadas condições climáticas quando da sua aplicação e, ainda, quando aplicadas sobre suportes absorventes (blocos cerâmicos). Quanto maior o teor de finos, maior é a quantidade de poros de pequeno diâmetro na argamassa endurecida, o que ajuda a reter mais água no seu interior e, consequentemente, promove maior hidratação na interface contribuindo para melhorar a ancoragem da argamassa [13]. Elevada retenção de água permite evitar, não só a sucção rápida da água por parte do suporte, como a perda excessiva de água de amassadura durante o processo de endurecimento. A quantidade de água retida aumentou com o teor de resíduos. Assim, o resíduo fino em substituição ao agregado, juntamente com a cal, resultou em excelente capacidade de reter água, o que pode não permitir a absorção excessiva de água pela alvenaria. Foi possível verificar que o teor de ar incorporado nas argamassas produzidas com RPP diminuiu quando comparada com a argamassa de referência (Fig. 4d). Tal fato ocorreu pelo aumento da densidade de massa das argamassas com RPP, o que garantiu menor quantidade de água livre disponível para a formação de bolhas. Desta forma, o aprisionamento de ar nas misturas foi menor. $\mathrm{O}$ principal mecanismo de formação de bolhas em pastas, argamassas e concretos é a entrada de ar durante o processo de mistura e agitação dos materiais [14]. O excesso de ar incorporado é responsável por problemas de acabamento e/ ou aderência, causando o descolamento do revestimento.

\section{Caracterização das argamassas no estado endurecido}

Os resultados dos ensaios de resistência à tração na flexão e resistência à compressão estão apresentados na Tabela IV. A resistência à tração para a idade de 90 dias mostrou que o acréscimo do teor de RPP não produziu alterações perceptíveis. Todas as misturas obtiveram a mesma classificação segundo a norma [15]. Quanto à análise dos resultados de resistência à compressão, percebeu-se que o aumento no teor de resíduo melhorou a resistência das argamassas, em comparação à argamassa de referência. À medida que a concentração de resíduo aumentou, a resistência à compres- 
Tabela IV - Resistência à tração na flexão (RTF) e resistência à compressão (RC) das argamassas.

[Table IV - Bending tensile strength (RTF) and compressive strength $(R C)$ of mortars.]

\begin{tabular}{ccc}
\hline Argamassa & RTF $(\mathrm{MPa})$ & RC $(\mathrm{MPa})$ \\
\hline $\mathrm{A} / 0 / \mathrm{REF}$ & $0,25 \pm 0,03$ & $0,5 \pm 0,1$ \\
$\mathrm{~A} / 5 / \mathrm{RPP}$ & $0,34 \pm 0,04$ & $0,7 \pm 0,1$ \\
$\mathrm{~A} / 10 / \mathrm{RPP}$ & $0,43 \pm 0,05$ & $1,2 \pm 0,2$ \\
$\mathrm{~A} / 15 / \mathrm{RPP}$ & $0,39 \pm 0,05$ & $1,8 \pm 0,2$ \\
$\mathrm{~A} / 20 / \mathrm{RPP}$ & $0,53 \pm 0,10$ & $2,1 \pm 0,3$ \\
$\mathrm{~A} / 25 / \mathrm{RPP}$ & $0,34 \pm 0,04$ & $1,9 \pm 0,2$ \\
$\mathrm{~A} / 30 / \mathrm{RPP}$ & $0,27 \pm 0,03$ & $1,9 \pm 0,1$ \\
\hline
\end{tabular}

Tabela V - Absorção de água por capilaridade (AAc) das argamassas.

[Table V-Capillary water absorption (AAc) of mortars.]

\begin{tabular}{cc}
\hline Argamassa & AAc, $\mathrm{t}=90 \mathrm{~min}\left(\mathrm{~g} / \mathrm{cm}^{2}\right)$ \\
\hline A/0/REF & $0,25 \pm 0,03$ \\
A/5/RPP & $0,34 \pm 0,04$ \\
A/10/RPP & $0,43 \pm 0,05$ \\
A/15/RPP & $0,39 \pm 0,05$ \\
A/20/RPP & $0,53 \pm 0,10$ \\
A/25/RPP & $0,34 \pm 0,04$ \\
A/30/RPP & $0,27 \pm 0,03$ \\
\hline
\end{tabular}

são das argamassas aumentou, o que foi relacionado com a densidade de massa aparente. Os resultados obtidos demonstraram que as argamassas contendo entre 10 e $20 \%$ de RPP apresentaram as maiores resistências em relação à argamassa de referência. No que se refere ao comportamento mecânico de todas as argamassas, os resultados dos ensaios realizados aos 90 dias de cura comprovaram que os valores das resistências são relativamente baixos. Contudo, em se tratando de argamassas para aplicação em alvenarias de edifícios antigos, os valores são aceitáveis de acordo com a classificação das argamassas segundo norma europeia [16].

Os dados da Tabela V mostram que a substituição de agregado por RPP na faixa de 10 a $20 \%$ promoveu absorção de quantidades ligeiramente maiores de água nas argamassas. Os corpos de prova alcançaram a saturação aos $90 \mathrm{~min}$ de contato com a água. A penetração da água é inversamente proporcional ao diâmetro dos capilares, ou seja, quanto menor o diâmetro dos capilares maior é a altura que a água atinge no corpo de prova. Este fato foi relacionado ao menor diâmetro das partículas do RPP, permitindo assim a formação de poros com diâmetros menores e, possivelmente, a ocorrência de conectividade entre eles.

A avaliação qualitativa da retração efetuada com base na observação visual das argamassas aplicadas revelou sinais de variações dimensionais mais significativas na zona dos topos das formas, principalmente nas argamassas com

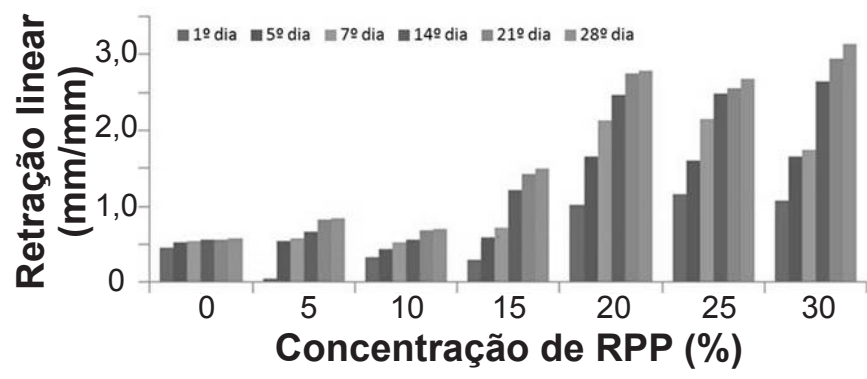

Figura 5: Retração linear das argamassas. [Figure 5: Linear retraction of mortars.]

maior teor de resíduo, no decorrer dos 28 dias. Porém, em nenhuma das situações analisadas registrou-se fissuração nos corpos de provas. A Fig. 5 mostra que ocorreu aumento na retração linear em todas as argamassas formuladas com RPP, com mais destaque para as argamassas com teores de 20 a $30 \%$ de resíduo. Possivelmente, este fato foi relacionado ao maior teor de finos presentes no resíduo, permitindo assim a formação de poros com diâmetro menor e consequentemente maior retenção de água. Ressalta-se que, além do aumento de teor de finos, a retração também se dá por carbonatação em que a cal hidratada reage com o gás carbônico presente no ar, formando carbonato de cálcio. Esta reação é acompanhada de redução de volume. Este comportamento é importante para o bom desempenho das argamassas, já que a fissuração condiciona fortemente a durabilidade das argamassas aplicadas como revestimento de edifícios antigos. Argamassas de cal absorvem pequenas tensões provocadas por movimentos de acomodação desiguais das estruturas. A capacidade de autorreparo de muitas pequenas fissuras que ocorrem no decorrer do tempo, ou seja, reconstituição autógena das fissuras, deve-se à carbonatação da cal que demanda tempos prolongados para se completar [17].

Por fim, a resistência de aderência à tração foi maior para as argamassas com RPP em relação à de referência (Tabela VI). Esta propriedade está associada à capacidade da argamassa de absorver tensões normais ou tangenciais na interface com o suporte. Isto revela a capacidade para resistir

Tabela VI - Resistência de aderência à tração das argamassas. [Table VI - Tensile adhesion strength of mortars.]

\begin{tabular}{ccccccc}
\hline $\begin{array}{c}\text { Teor de } \\
\text { resíduo }(\%)\end{array}$ & Taxa & \multicolumn{2}{c}{ RAT } & \multicolumn{4}{c}{ Forma de ruptura } \\
$(\mathrm{N} / \mathrm{s})$ & $(\mathrm{MPa})$ & $\mathrm{A}$ & $\mathrm{B}$ & $\mathrm{C}$ & $\mathrm{D}$ \\
\hline 0 & 50 & 0,02 & $\mathrm{X}$ & & & \\
5 & 80 & 0,08 & $\mathrm{X}$ & & & \\
10 & 80 & 0,12 & $\mathrm{X}$ & $\mathrm{X}$ & & \\
15 & 80 & 0,11 & $\mathrm{X}$ & $\mathrm{X}$ & & \\
20 & 80 & 0,15 & $\mathrm{X}$ & $\mathrm{X}$ & & \\
25 & 80 & 0,11 & $\mathrm{X}$ & $\mathrm{X}$ & & \\
30 & 80 & 0,10 & $\mathrm{X}$ & $\mathrm{X}$ & & \\
\hline
\end{tabular}


deformações por tração e por cisalhamento, sem danos, tais como destacamentos, sendo esta uma das patologias mais comuns em alvenarias de prédios antigos [18]. Os resultados representam médias de seis corpos de prova de cada argamassa, no total de 42 arrancamentos, das tensões obtidas em cada ensaio com o respectivo tipo de ruptura no momento do arrancamento. As formas de ruptura possíveis são: A) na interface argamassa/substrato; B) no interior da argamassa de revestimento; C) no substrato; D) na interface revestimento/cola; E) na interface cola/pastilha. Nos casos em que a ruptura ocorre na interface cola-argamassa ou colapastilha (D e E), o valor registrado não é considerado válido. Para efeito de aderência, consideram-se as formas de ruptura A, B e C. A adição de RPP adicionou a forma de ruptura do modo $\mathrm{B}$, contudo a resistência à aderência aumentou significativamente.

\section{CONCLUSÕES}

Argamassas de reparo à base de cal foram formuladas com adição de resíduo do polimento de porcelanato (RPP) substituindo parcialmente a areia. O RPP possuiu composição química e cristalográfica característica da mistura de quartzo, mulita e $\mathrm{SiC}$, utilizado como abrasivo no polimento. O RPP apresentou-se como um pó fino com partículas entre 1 e 44 $\mu \mathrm{m}$ e diâmetro médio de $5,93 \mu \mathrm{m}$, confirmando o potencial do material para preenchimento de poros na argamassa endurecida. Os ensaios no estado fresco revelaram que as argamassas com RPP necessitaram de maiores quantidades de água em comparação com a argamassa de referência para atingir a mesma consistência $(260 \pm 5 \mathrm{~mm})$. As argamassas contendo RPP apresentaram maior densidade e compacidade pela ação dos finos do RPP. A substituição parcial de areia por RPP melhorou a trabalhabilidade, consistência, coesão e plasticidade em relação à argamassa de referência. Observou-se maior retenção de água, melhor densidade aparente e menor teor de ar incorporado, resultando em materiais com melhor espalhamento, o que explicou a melhor aderência entre argamassa e substrato. No estado endurecido, as argamassas apresentaram maiores resistências à compressão em relação à argamassa padrão. As argamassas com concentrações de RPP de até $15 \%$ apresentaram maior ganho na retração livre que as demais. Por fim, a adição de resíduos resultou em maiores resistências de aderência à tração. Portanto, a adição de RPP em substituição parcial da areia resultou em um melhor conjunto de características físicas e mecânicas, o que sugere melhor desempenho e maior durabilidade, contribuindo para o restauro arquitetônico e preservação do patrimônio histórico.

\section{AGRADECIMENTOS}

Os autores agradecem à CAPES, à Universidade Federal do Rio Grande do Norte (UFRN) e ao Instituto Federal de Educação, Ciência e Tecnologia da Bahia (IFBA) pelo apoio indispensável à realização desse trabalho. Agradecem, ainda, à empresa Eliane S.A. Revestimentos Cerâmicos pela concessão de amostra de resíduo do polimento de porcelanato.

\section{REFERÊNCIAS}

[1] L.M. Scartezini, H. Carasek, in Simp. Bras. Tecnol. Argamassas, 5, S. Paulo (2003) 233-246.

[2] A.M. Bernardin, Cerâm. Ind. 11, 5/6 (2006) 31-34.

[3] S.L.M. Almeida, "Aproveitamento de rejeitos de pedreiras de Santo Antônio de Pádua, RJ para produção de brita e areia", Tese Dr., Univ. S. Paulo, S. Paulo (2001). [4] Assoc. Bras. Nor. Técn., NBR 13276, “Argamassa para assentamento e revestimento de paredes e tetos - preparo da mistura e determinação de consistência, Rio de Janeiro (1995).

[5] Assoc. Bras. Nor. Técn., NBR 13278, “Argamassa para assentamento e revestimento de paredes e tetos - determinação da densidade de massa e do teor de ar incorporado", Rio de Janeiro (2005).

[6] Assoc. Bras. Nor. Técn., NBR 13277, “Argamassa para assentamento e revestimento de paredes e tetos determinação da retenção de água”, Rio de Janeiro (1995). [7] Assoc. Bras. Nor. Técn., NBR 13276, "Argamassa para assentamento e revestimento de paredes e tetos - preparo da mistura e determinação de consistência", Rio de Janeiro (2005).

[8] Assoc. Bras. Nor. Técn., NBR 13279, “Argamassa para assentamento e revestimento de paredes e tetos - determinação da resistência à tração na flexão e à compressão", Rio de Janeiro (2005).

[9] Assoc. Bras. Nor. Técn., NBR 15259 “Argamassa para assentamento e revestimento de paredes e tetos determinação da absorção de água por capilaridade e do coeficiente de capilaridade", Rio de Janeiro (2005).

[10] Assoc. Bras. Nor. Técn., NBR 15261, "Argamassa para assentamento e revestimento de paredes e tetos - determinação da variação dimensional (retração ou expansão linear)", Rio de Janeiro (2005).

[11] Assoc. Bras. Nor. Técn., NBR 15258, “Argamassa para revestimento de paredes e tetos - determinação da resistência potencial de aderência à tração", Rio de Janeiro (2005).

[12] Assoc. Bras. Nor. Técn., NBR 13281, "Requisitos", Rio de Janeiro (1995).

[13] E. Pereira, I.J. da Silva, M.R.M.M. Costa, Ambient. Constr. 13, 2 (2013) 139-149.

[14] M.A. Cincotto, "Argamassas de revestimento: características, propriedades e métodos de ensaio", Bol. Técn. 68, Inst. Pesq. Tecnol., S. Paulo (1995).

[15] Assoc. Bras. Nor. Técn., NBR 13281, “Argamassa para assentamento e revestimento de paredes e tetos requisitos", Rio de Janeiro (1995).

[16] Eur. Comm. Stand., EN 1015-8, "Methods of test for mortar for masonry - part 8: determination of water retentivity of fresh mortar", Brussels (1999).

[17] J.E.P. Guimarães, A cal: fundamentos e aplicações na engenharia civil, PINI, S. Paulo (1998).

[18] C.S. Kazmierczak, D.E. Brezezinski, D. Collatto, Estud. Tecnol. Eng. 3, 1 (2007) 47-58.

(Rec. 31/10/2016, Rev. 25/11/2016, Ac. 31/12/2016) 